\title{
Erratum: Spatial variability of streambed vertical hydraulic conductivity and its relation to distinctive stream morphologies in the Beiluo River, Shaanxi Province, China
}

\author{
Weiwei Jiang ${ }^{1} \cdot$ Jinxi Song ${ }^{1,2}$ • Junlong Zhang ${ }^{1}$ • \\ Yuanyuan Wang ${ }^{1} \cdot$ Nan Zhang $^{3} \cdot$ Xinhua Zhang $^{4}$. \\ Yongqing Long ${ }^{1} \cdot$ Jiaxuan $\mathrm{Li}^{1} \cdot$ Xiaogang Yang ${ }^{1}$
}

Published online: 18 September 2015

(C) Springer-Verlag Berlin Heidelberg 2015

Erratum to: Hydrogeology Journal (2015)

DOI: $10.1007 / \mathbf{s 1 0 0 4 0 - 0 1 5 - 1 2 8 8 - 4}$

A grant number in the Acknowledgments has been corrected: This study was jointly supported by the National Natural Science Foundation of China (Grant Nos. 51079123, 51379175 and 51309107).

1 College of Urban and Environmental Sciences, Northwest University, Xi'an, 710027, China

2 State Key Laboratory of Soil Erosion and Dryland Farming on the Loess Plateau, Institute of Soil and Water Conservation, CAS \& MWR, Yangling, 712100, China

3 Yellow River Institute of Hydraulic Research, Zhengzhou, 450003, China

4 State Key Laboratory of Hydraulics and Mountain River Engineering, Sichuan University, Chengdu, 610065, China 